\title{
Does Choosing a Treatment Depend on Making a Diagnosis? US and French Physicians' Decision Making about Acute Otitis Media
}

\author{
PAUL CLAY SORUM, MD, PhD, THOMAS R. STEWART, PhD, ETIENNE MULLET, PhD, \\ CLAUDIA GONZÁLEZ-VALLEJO, PhD, JUNSEOP SHIM, PhD, GÉRARD CHASSEIGNE, PhD, \\ MARÍA TERESA MUÑOZ SASTRE, PhD, BERNARD GRENIER, MD
}

\begin{abstract}
Background. The classic sequential processing model of clinical decision making-in which the treatment choice follows and depends on the diagnostic judgment-may in some cases be replaced by a processing model in which the treatment choice depends on an independent assessment of the diagnostic and other cues. The aim of this study was to determine which processing model would better describe physicians' treatment choices in a simulated clinical task. Methods. Seventy-five US and French primary care physicians were presented twice, in a different order, with the same set of 46 scenarios of 15-month-old children suspected of having acute otitis media (AOM). They rated in one set the probability of AOM and in the other set whether they would treat the child with antibiotics (and how confident they felt in their decision). Linear regression analyses revealed the individuals' 2 judgment policies. Hierarchical discriminant anal-
\end{abstract}

ysis was used to analyze the variance explained in the treatment choice by, 1st, the diagnostic judgment, 2nd, the cues specific to treatment, and 3rd, the cues specific to diagnosis. Results. Even when choosing treatment, the participants placed greatest weight on diagnostic cues, especially the ear findings. Only $28 \%$ used the cues that reflected parental issues. For $36 \%$, the diagnostic cues had an effect on the treatment choice independent of the effect (if any) of the diagnostic judgment. Conclusion. In deciding how to treat AOM, the majority of the participating US and French primary care physicians followed the classic sequential processing model, but a substantial minority used instead an independent processing model. Key words: decision making; judgment analysis; acute otitis media. (Med Decis Making 2002;22: 394-402)
$\mathbf{I}_{\mathrm{v}}^{\mathrm{n}}$ n making medical decisions, a physician interprets a variety of cues-including history, physical exam, test results, medication effects, costs, and patient preferences-to make a diagnosis and choose a course of treatment. In the classic paradigm, this process is sequential: first, the physician uses the cues pertinent to diagnosis to make a diagnostic judgment, and subsequently, based on that diagnostic judgment and other cues relevant to treatment, he or she chooses a treatment. As Barrows and Pickell insist, "A diagnostic decision has to be made before you treat."1(p149) This sequential paradigm underlies the threshold model of decision making propounded by Pauker and Kassirer ${ }^{2}$ and others ${ }^{3,4}$ : the physician judges the probability of a particular diagnosis and then chooses an action (e.g.,

DOI: $10.1177 / 027298902236941$ further testing, treatment, watchful waiting) depending on whether the judged probability passes the testing or treatment threshold.

Received 8 June 2001 from the Departments of Medicine and Pediatrics, Albany Medical Center, Albany, New York (PCS); the Center for Policy Research, University of Albany, Albany, New York (TRS, JS); the École Pratique des Hautes Études, Toulouse, France (EM); the Department of Psychology, Ohio University, Athens, Ohio (CG); the Département de Psychologie, Université François-Rabelais, Tours, France (GC); the Département de Psychologie, Université du Mirail, Toulouse, France (MTMS); and the Faculté de Médecine, Tours, France (BG). Revision accepted for publication 17 May 2002.

Address correspondence and reprint requests to Dr. Sorum, Albany Med Primary Care Network, 724 Watervliet-Shaker Road, Latham, NY 12110; phone: (518) 783-0312; fax: (518) 782-7485; e-mail: sorump@ mail.amc.edu. 
This sequential process may be more or less complicated, may involve choosing to obtain more information before making a diagnosis, will be iterative as more information is obtained, and will often necessitate initiating treatment even when the diagnosis remains uncertain. ${ }^{1,5}$ But the diagnostic judgment will and should, in this paradigm, precede the choice of treatment. The physician will use the diagnostic cues directly to make the judgment but only indirectly to choose a treatment. The relation between the cues, the diagnosis, and the choice of treatment can thus be schematized as shown in Figure 1 (top panel).

This paradigm has its roots in past centuries when the expertise of Western physicians was manifested in making accurate prognoses rather than in providing effective treatment. ${ }^{6}$ In the contemporary era, however, physicians' focus has shifted as treatments have become more effective, available, and publicized. ${ }^{7}$ The classic paradigm is called into question by further considerations. It is well known that judgments and choices are different cognitive tasks ${ }^{8}$; this difference is responsible, for example, for the preference reversals that can take place when people are asked first to give desirability ratings of things and subsequently to make choices among them. ${ }^{9-12}$ More important, the sequence of judgment and choice is violated in practice. Physicians often decide on treatment before arriving at a diagnosis, as in the case of a patient with a fever who looks sick whom the physician wants to treat with antibiotics or admit to the hospital. Similarly, investigators have suspected that diagnoses of bacterial respiratory infections, such as sinusitis or acute otitis media (AOM), are frequently made after a treatment has been chosen (i.e., when physicians want to justify the prescription of antibiotics ${ }^{13-15}$ ), just as people are known in other contexts to seek reasons to justify decisions they have already made. ${ }^{16}$

Accordingly, we propose an alternative model of clinical decision making in which the physician makes the diagnostic judgment and the treatment choice by means of a largely independent, often simultaneous processing of both the diagnostic and the treatment cues. This independent processing model is shown in Figure 1 (lower panel). In pure form, the diagnostic cues influence the treatment choice directly and separately from their influence on the diagnosis; the diagnostic judgment itself has no direct impact on the treatment choice. Graduations are, of course, possible between the 2 models depicted in Figure 1.

When Kassirer and Kopelman ${ }^{5}$ analyzed their recordings of physicians talking about their clinical problem solving as they were actually doing it, they found that expert physicians do not make a distinction be-

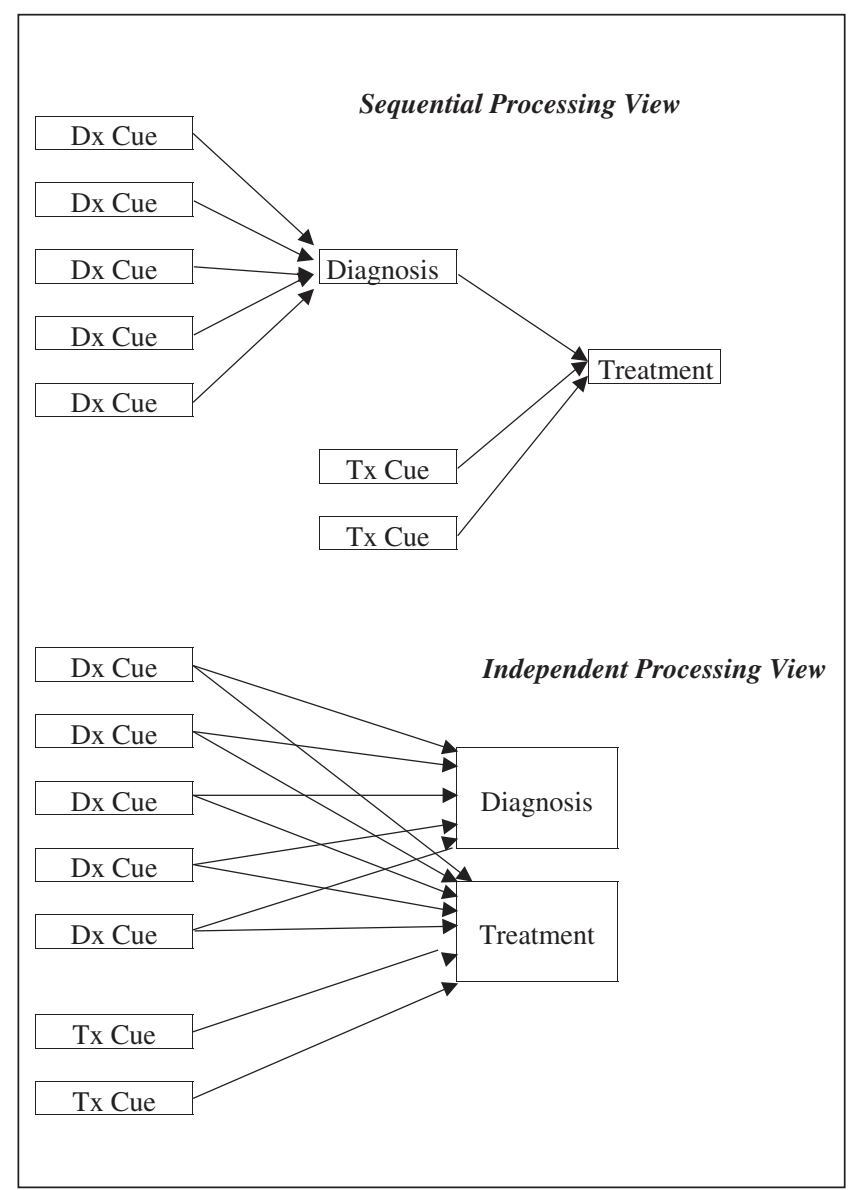

Figure 1 Two possible models of the decision-making process. $D x=$ diagnosis; $T x=$ treatment .

tween diagnostic and therapeutic decision-making tasks when they solve clinical problems. In discussing a particular case, Kassirer and Kopelman observed that the physician "did not first make a diagnosis and then decide how to treat; he made a preliminary diagnosis, started treatment, added further support to his diagnosis, and then continued treatment." ${ }^{(\mathrm{p} 220-1)}$ Even Kassirer's team, however, did little investigation of the relation between a diagnostic judgment and a therapeutic choice. ${ }^{5,17}$ Yet, it is important to ascertain the accuracy in clinical practice of the classical model because it is the paradigm taught to aspiring and practicing physicians.

Accordingly, we examined the relation between diagnosis and treatment in the decision making of US and French primary care physicians about young children who might have AOM, an acute bacterial infection of the middle ear. In our previous study of decision mak- 
ing about $\mathrm{AOM},{ }^{18}$ participating US pediatricians were asked in each case a diagnostic question (the probability of AOM) followed by a treatment question (watch or treat). The probability level predicted the treatment choice, in the sense that the pediatricians had a threshold for treatment of, on average, a $50 \%$ probability of AOM. But the design of sequential questions assumed a classic paradigm and may have influenced participants to answer in accordance with it; accordingly, it would not allow us to determine whether the classic paradigm was correct. In the current study, therefore, we separated the questions; in one part of the study, the participating physicians were asked the probability, in the other part, the choice of treatment. We expected to find that the process of decision making about $\mathrm{AOM}$ is, for many clinicians, closer to the independent than to the sequential processing model.

\section{METHODS}

The primary methodological framework of the study was "judgment analysis." "19,20 Judgment analysis is a method for modeling a person's implicit judgment strategy (usually called "judgment policy”), typically using multiple regression analysis. The data for judgment analysis consist of a set of judgments made by the person (usually, for practicability, about a set of paper scenarios) and the cues serving as predictors for those judgments (the pieces of information presented in the scenarios). This analysis yields a regression equation that describes that person's judgment policy. The beta weights are estimates of the relative importance of the cues in making judgments. Between- and within-group comparisons of these weights reveal how and why people differ in their judgments of identical cases.

\section{Participants}

The samples consisted of primary care practitioners from the United States and France. Although French cultural traditions are more rationalist and US more empiricist, ${ }^{21,22}$ physicians receive similar training in the 2 countries $^{23,24}$ and participate in the common culture of modern Western medicine. Accordingly, we neither expected to find differences in medical decision making nor designed the study to look for such differences. Furthermore, in our subsequent analyses, we found no differences. In this article, therefore, the clinicians of both countries are grouped together.

We enrolled a total of 75 physicians: 19 US family practitioners, 35 French general practitioners, and 21 French pediatricians. The US physicians were recruited from the 62 family practitioners of the region of
Albany and Schenectady, New York, by written and oral appeals from the study team; we had already studied the area pediatricians. ${ }^{18}$ The French general practitioners were recruited by telephone, e-mail, and mail from approximately 150 acquaintances or members of 2 networks of research-minded general practitioners. The French pediatricians were recruited by written appeals to the 30 practicing pediatricians in and around Tours. The research was approved by the institutional review boards at Albany Medical Center and the University at Albany.

\section{Procedure}

The participants were presented twice with 46 paper scenarios describing hypothetical 15-month-old children who might have an ear infection. The sets of scenarios were in 2 randomly determined orders. As shown in Figure 2, each scenario displayed the values for 15 different cues felt by the physicians and parents we consulted to be important for decisions about diagnosis and treatment of AOM. The diagnostic cues were also based on our previous study of US pediatricians ${ }^{18}$ and on the medical literature in the United States, ${ }^{25-27}$ France, ${ }^{28,29}$ and elsewhere. ${ }^{30,31}$ The cue values for each case were generated randomly by a computer program. Very implausible combinations of cue values were, however, excluded from the scenarios. The cues, their possible values, and the exclusion rules are listed in Table 1. Small to moderate correlations between the values of the individual cues in the 46 cases, ranging from -0.40 to +0.39 , resulted either from the generation rules (e.g., +0.39 between bulging and mobility) or from chance (e.g., -0.40 between a history of ear pain and ear pain during the exam). These intercorrelations were in accordance with the literature on clinical features of $\mathrm{AOM}^{25-31}$ and were felt by the study physicians to be plausible.

The participants were asked to place themselves in the role of the examining physician. During one series of scenario judgments, they were to judge the probability that each child had AOM and mark it on a linear scale anchored by 0 and 100. During the other series of judgments (illustrated in Fig. 2), in which the cases were presented in a different random order, they were to decide whether to treat with antibiotics or to observe the child. Half of the participants were given the diagnosis set first, and half were given the treatment set first. They made their diagnoses and treatment decisions at home and were instructed to take a short break of up to 1 day between the 2 sets. The sets were in separate envelopes; the one to be completed 1st was clearly marked. Participants were asked not to change their an- 


\section{Case 1}

History

\begin{tabular}{|rcc|}
\hline Past history of AOM & & \\
URI symptoms & None & Frequent \\
Ear pain noted by parent & No & Yes \\
& $\square$ & No \\
\hline
\end{tabular}

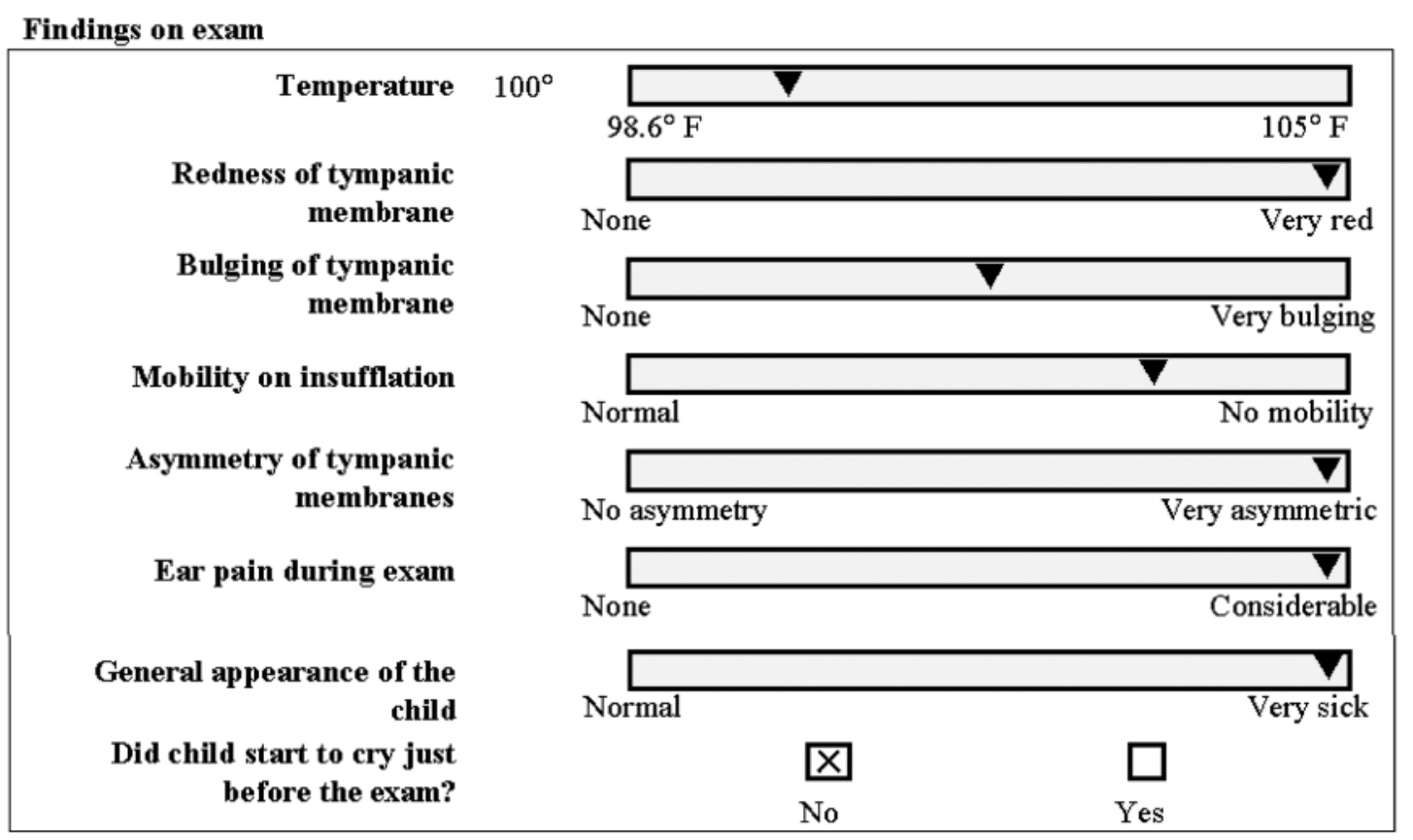

\section{Other factors}

Parents' personal position concerning antibiotics

Ability of parents to provide effective care to a sick child

Does caring for sick child greatly upset parents' ordinary schedule?

Are there babies or other small children in the family?

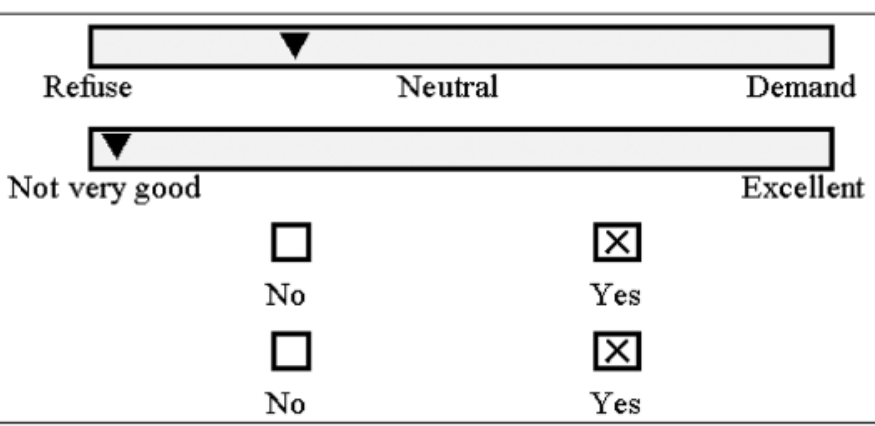

Observe the child Prescribe antibiotics

What would you do in this case? Please select one option:

Are you sure that this is the right thing to do at this point?

Not at all sure Completely sure

Figure 2 Example of scenario and treatment question. AOM = acute otitis media; URI = upper respiratory tract infection. 
swers and not to look back at the 1st set while working on the 2nd set.

\section{Data Analysis}

To obtain descriptions of the physicians' judgment policies, 2 analyses were performed for each participant. In the 1st analysis, multiple linear regression analysis was used to fit a model predicting the judgment of the probability of AOM from the 15 cues. Because treatment choices were binary (antibiotics or observe), we used a 2-group discriminant analysis to model them. This was calculated by using a standard regression analysis with the treatment choice coded 0 (observe) or 1 (treat with antibiotics). We chose discriminant analysis rather than logistic regression analysis to model treatment decisions because discriminant analysis yields discriminant function weights that are directly comparable to the regression weights calculated for the diagnosis decision. These analyses yielded, for each participant, a multiple correlation and cue weights (standardized regression weights in the case of the diagnostic judgments and standardized discriminant function weights in the case of the treatment decisions). A participant's weights were included in further analyses only if his or her $R^{2}$ passed the $F$ test for fitness of the multiple regression model at $P<0.05$. The significance of the difference between the mean cue weights for diagnosis and treatment were calculated by $t$ tests. Because the sample distributions of the cue weights were approximately symmetric, no transformation was performed before doing the analysis.

Subsequently, a hierarchical discriminant analysis was computed for each physician with the treatment choice (to treat or observe) as the dependent variable. In this analysis, variables are entered in sequential sets, and the significance of the incremental variance accounted for by each set is determined by an $F$-test. The order of entry of the sets of variables was chosen to distinguish between the independent and sequential processing models. Examination of the models described in Figure 1 reveals 3 sets of predictor variables: 1) the diagnostic cues, 2) the treatment cues, and 3) the diagnostic judgment itself. The critical difference between the 2 models is in the role of the diagnostic cues. In the sequential processing view, the diagnostic cues have no direct impact on the treatment decision. They only influence the diagnosis, which in turn influences the treatment. In this case, the diagnostic cues should account for no additional variance over the diagnosis itself. In contrast, the independent model predicts a di-
Table 1 Possible Values of the 15 Cues

\begin{tabular}{|c|c|c|}
\hline Name of Cue & $\begin{array}{l}\text { Number of } \\
\text { Options }\end{array}$ & $\begin{array}{c}\text { Range } \\
\text { (or Anchors) }\end{array}$ \\
\hline \multicolumn{3}{|l|}{ Past history of acute } \\
\hline $\begin{array}{l}\text { Upper respiratory tract } \\
\text { infection symptoms }{ }^{\mathrm{a}}\end{array}$ & 2 & No, yes \\
\hline Ear pain noted by parents & 2 & No, yes \\
\hline Temperature & 10 & $98.6^{\circ} \mathrm{F}, 105^{\circ} \mathrm{F}$ \\
\hline $\begin{array}{l}\text { Redness of tympanic } \\
\text { membrane }\end{array}$ & 5 & None, very red \\
\hline $\begin{array}{l}\text { Bulging of tympanic } \\
\text { membrane }\end{array}$ & 5 & None, clearly evident \\
\hline Mobility on insufflation & 5 & Normal, no mobility \\
\hline $\begin{array}{l}\text { Asymmetry of tympanic } \\
\text { membrane }\end{array}$ & 5 & Normal, very asymmetric \\
\hline Ear pain during exam & 5 & None, considerable \\
\hline $\begin{array}{l}\text { General appearance of } \\
\text { the child }\end{array}$ & 5 & Normal, very sick \\
\hline $\begin{array}{l}\text { Did child start to cry just } \\
\text { before the exam? }\end{array}$ & 2 & No, yes \\
\hline $\begin{array}{l}\text { Parents' personal position } \\
\text { concerning antibiotics }\end{array}$ & n & Refuse, neutral, demand \\
\hline $\begin{array}{l}\text { Ability of parents to } \\
\text { provide effective care to } \\
\text { a sick child }\end{array}$ & o & Not very good, excellent \\
\hline $\begin{array}{l}\text { Does caring for sick child } \\
\text { greatly upset parents' } \\
\text { ordinary schedule? }\end{array}$ & d & No, yes \\
\hline $\begin{array}{l}\text { Are there babies or other } \\
\text { small children in the } \\
\text { family? }\end{array}$ & r & No, yes \\
\hline
\end{tabular}

Note: Rules for excluding implausible combinations are as follows: do not allow value \#1 on mobility and value \#4 or \#5 on bulging, do not allow \#1 on appearance and \#6 through \#10 on temperature, and do not allow \#5 on asymmetry and \#1 on both redness and bulging.

a. Physicians would interpret "upper respiratory tract infection symptoms" as referring primarily to nasal congestion and discharge, possibly accompanied by cough, poor eating, irritability, and fever.

rect influence of the diagnostic cues on the treatment choice.

In our analysis, the 1st predictor set entered (a set containing only 1 variable) was the diagnostic judgment (0-100). The cues that were specific to treatment (e.g., the position of the parents with regard to the use of antibiotics, the parents' ability to take care of a sick child, the impact of the illness on the parents' schedule, the presence of other children) were added to the model in the 2nd set. This 2nd set of cues was included in this analysis to control for the possibility that the di- 
Table 2 Physicians' Judgment Policies for Acute Otitis Media: Mean Beta Weights for Diagnosis and Treatment

\begin{tabular}{|c|c|c|c|c|c|}
\hline \multirow[b]{2}{*}{ Variable } & \multicolumn{4}{|c|}{ Mean Weights } & \multirow{2}{*}{$\begin{array}{c}\text { Significance of } \\
\text { Diagnosis/Treatment } \\
\text { Difference } \\
(n=64)^{\mathrm{a}}\end{array}$} \\
\hline & \multicolumn{2}{|c|}{$\begin{array}{c}\text { Diagnosis } \\
\text { Probability } \\
\quad(n=74)\end{array}$} & \multicolumn{2}{|c|}{$\begin{array}{c}\text { Treatment } \\
\text { Decision } \\
(n=65)\end{array}$} & \\
\hline \multicolumn{6}{|l|}{ History } \\
\hline Past history of acute otitis media & 0.030 & $(0.145)$ & 0.020 & $(0.133)$ & 0.692 \\
\hline Upper respiratory tract infection symptoms & 0.023 & $(0.149)$ & 0.044 & $(0.164)$ & 0.733 \\
\hline Ear pain noted by parent & 0.056 & $(0.136)$ & 0.076 & $(0.159)$ & 0.204 \\
\hline \multicolumn{6}{|l|}{ Findings on exam } \\
\hline Temperature & 0.173 & $(0.151)$ & 0.231 & $(0.179)$ & 0.079 \\
\hline Redness of tympanic membrane & 0.425 & $(0.238)$ & 0.327 & $(0.183)$ & $<0.001$ \\
\hline Bulging of tympanic membrane & 0.418 & $(0.216)$ & 0.326 & $(0.198)$ & $<0.001$ \\
\hline Mobility on insufflation & 0.189 & $(0.211)$ & 0.138 & $(0.181)$ & 0.006 \\
\hline Asymmetry of tympanic membranes & 0.163 & $(0.124)$ & 0.147 & $(0.152)$ & 0.464 \\
\hline Ear pain during exam & 0.088 & $(0.158)$ & 0.044 & $(0.147)$ & 0.174 \\
\hline General appearance of the child & 0.041 & $(0.134)$ & 0.092 & $(0.153)$ & 0.004 \\
\hline Did the child start to cry just before the exam? & -0.002 & $(0.116)$ & 0.032 & $(0.104)$ & 0.059 \\
\hline \multicolumn{6}{|l|}{ Other factors } \\
\hline $\begin{array}{l}\text { Parents' personal position concerning antibiotics } \\
\text { Ability of parents to provide effective care to a }\end{array}$ & 0.015 & $(0.112)$ & 0.141 & $(0.175)$ & $<0.001$ \\
\hline sick child & -0.014 & $(0.121)$ & -0.045 & $(0.184)$ & 0.214 \\
\hline $\begin{array}{l}\text { Does caring for sick child greatly upset parents' } \\
\text { ordinary schedule? }\end{array}$ & 0.001 & $(0.116)$ & 0.015 & (0.138) & 0.255 \\
\hline $\begin{array}{l}\text { Are there babies or other small children in } \\
\text { the family? }\end{array}$ & -0.001 & (0.091) & 0.038 & $(0.114)$ & 0.005 \\
\hline
\end{tabular}

Note: Standard deviations are in parentheses.

a. Only doctors whose models were significant for both treatment and diagnosis were included in the $t$ tests. Significant differences, after Bonferroni adjustment to account for multiple tests, are in bold.

agnostic cues were significantly correlated with the treatment cues. The 3rd set included the cues that were relevant to the diagnosis-the cues describing history and physical exam (e.g., history of AOM, upper respiratory tract infection symptoms, ear pain noted by parent, temperature, redness of tympanic membrane, bulging of tympanic membrane, mobility on insufflation, asymmetry of tympanic membranes, crying during exam, overall appearance of child). Under the sequential processing model, sets 1 and possibly 2 would be significant, but not set 3 . Under the independent processing model, set 3 would be significant (whether or not sets 1 and/or 2 were also significant). Thus, the 2 models make different predictions with regard to set 3 .

We used a chi-square test to test for the effect of order (whether the diagnosis or treatment scenarios were presented first) on the results of the hierarchical discriminant analysis.

\section{RESULTS}

\section{Judgment Policies}

One way to compare diagnostic judgments and treatment decisions is to compare cue utilization. Table 2 shows the mean weights (standardized regression weights and discriminant function weights) for each cue in judging the probability of AOM and choosing a treatment. Like the US pediatricians in our earlier study, ${ }^{18}$ the physicians here relied primarily on the physical exam of the tympanic membrane both in diagnosing AOM and in deciding how to treat the children. Treatment decisions were influenced a little less by the tympanic membrane and a little more by other factors, namely, the parents' position on antibiotics. In general, however, the cues presumed to be particularly relevant to treatment (the "other factors" in Table 2) were given little weight even in making treatment decisions. 
Table 3 Results of Discriminant Analysis of Treatment Choice $(N=75)$

\begin{tabular}{|c|c|c|c|}
\hline Set & Variables Entered & $\begin{array}{c}\text { Number of } \\
\text { Significant } \\
\text { Results } \\
(P<0.05)\end{array}$ & $\begin{array}{l}\text { Percentage } \\
\text { of Significant } \\
\text { Results }\end{array}$ \\
\hline 1 & $\begin{array}{l}\text { Diagnosis (probability of } \\
\text { acute otitis media) }\end{array}$ & 72 & 96.0 \\
\hline 2 & Treatment cues & 21 & 28.0 \\
\hline 3 & Diagnostic cues & 27 & 36.0 \\
\hline \multicolumn{4}{|c|}{$\begin{array}{l}\text { Note: Diagnosis: the judgment of the probability of acute otitis media in the } \\
\text { same set of scenarios when asked for diagnosis rather than for treatment. } \\
\text { Diagnostic cues: history of acute otitis media, upper respiratory tract infec- } \\
\text { tion symptoms, ear pain noted by parent, temperature, redness of tympanic } \\
\text { membrane, bulging of tympanic membrane, mobility on insufflation, } \\
\text { asymmetry of tympanic membranes, crying during exam, and overall ap- } \\
\text { pearance of child. Treatment cues: position of the parents with regard to the } \\
\text { use of antibiotics, parents' ability to take care of a sick child, impact of the } \\
\text { illness on the parents' schedule, and presence of other children. }\end{array}$} \\
\hline
\end{tabular}

There was considerable variability among participants in the usage of the cues. The standard deviations of the beta weights for the 15 cues ranged from 0.091 to 0.238 for diagnosis and from 0.104 to 0.198 for treatment.

\section{Processing Model for Treatment}

The results of the hierarchical discriminant analysis of the treatment choice are shown in Tables 3 and 4. The treatment choices of 27 physicians (36\%) can be described by some version of the independent processing model, and the choices of $47(63 \%)$ can be described by the classic sequential model. The treatment cues had a significant influence for only 21 (28\%) of the physicians.

The results of this analysis did not differ significantly by order of presentation of the 2 sets of profiles.

Table 4 provides additional details about the results. Among the 27 doctors for whom the results supported the independent processing model, 19 appeared not to use the treatment cues at all. Similarly, among the 47 doctors whose results suggested sequential processing, 32 did not appear to use the treatment cues. Thus, regardless of which processing model was used, most doctors did not make use of the treatment cues.

\section{DISCUSSION}

The judgment analysis revealed that the cues used by both the US and French primary care physicians to choose whether or not to treat children with antibiotics for possible AOM were largely the same as the cues
Table 4 Interpretation of Results of Discriminant Analysis

\begin{tabular}{|c|c|c|c|c|}
\hline \multicolumn{3}{|c|}{ Significance } & \multirow{2}{*}{$\begin{array}{l}\text { Number } \\
\text { of } \\
\text { Physicians } \\
\text { (\%) }\end{array}$} & \multirow[b]{2}{*}{ Interpretation } \\
\hline Set 1 & Set 2 & Set 3 & & \\
\hline No & No & No & $1 \quad(1.3)$ & $\begin{array}{l}\text { Failure-treatment decision } \\
\text { not related to cues or } \\
\text { diagnosis }\end{array}$ \\
\hline No & No & Yes & $2 \quad(2.7)$ & $\begin{array}{l}\text { Independent processing } \\
\text { model-treatment decision } \\
\text { based only on diagnosis } \\
\text { cues, not on diagnosis } \\
\text { judgment or treatment cues }\end{array}$ \\
\hline Yes & No & Yes & $19(25.3)$ & $\begin{array}{l}\text { Independent processing } \\
\text { model—treatment based on } \\
\text { diagnosis plus diagnosis } \\
\text { cues }\end{array}$ \\
\hline Yes & Yes & Yes & $6 \quad(8.0)$ & $\begin{array}{l}\text { Independent processing } \\
\text { model—treatment based on } \\
\text { diagnosis, diagnosis cues, } \\
\text { and treatment cues }\end{array}$ \\
\hline Yes & No & No & $32(42.7)$ & $\begin{array}{l}\text { Sequential processing model, } \\
\text { with no consideration of } \\
\text { treatment cues-treatment } \\
\text { based only on diagnosis }\end{array}$ \\
\hline Yes & Yes & No & $15(20.0)$ & $\begin{array}{l}\text { Sequential processing } \\
\text { model-treatment based on } \\
\text { diagnosis plus treatment } \\
\text { cues }\end{array}$ \\
\hline
\end{tabular}

Note: The diagnosis and treatment cues are described in Table 3. The independent processing and sequential processing models of decision making are illustrated in Figure 1.

they used to judge the probability of AOM. Only $28 \%$ made use of the treatment-oriented cues that had been added to the scenarios to provide them with the more complete set of the information physicians are increasingly asked to use when deciding on treatment. ${ }^{32-35}$ These findings appear to support the central importance of diagnosis for physicians in planning treatment.

Our hierarchical discriminant analysis demonstrated, however, that this initial conclusion must be revised. If diagnostic judgments largely determined treatment choices, we would expect that the diagnostic cues would have little additional impact on treatment choices beyond that of the diagnostic judgment (the judged probability of AOM). In fact, we found that $36 \%$ of the participants made significant use of the diagnosis 
cues independent of the effect (if any) of the diagnostic judgments.

It might seem unusual that the processing model used by the physicians was not related to the order of presentation of the 2 sets of cases. Upon reflection, however, it is clear that there was nothing to prevent a physician from using a sequential process for making treatment choices. She or he could first make a diagnostic judgment (even though the instructions did not ask for it) and then make the treatment choice. Even if the diagnostic set of judgments was made 1st, it is unlikely that the physician making a treatment decision would remember what diagnostic judgment she or he had previously made. It is not surprising, therefore, that order did not matter.

The study has several limitations. First, the convenience sample of primary care physicians was small in size and may not be representative. With such a heavy commitment of time, it was difficult to convince physicians to participate in the study. Second, the physicians made decisions about paper, rather than real, patients. Although the use of paper scenarios has been criticized, ${ }^{36,37}$ this method is practical and has been validated ${ }^{38-43}$ including specifically for AOM. ${ }^{38,40}$ Third, physicians may not want to acknowledge giving in to pressure from parents; consequently, the treatment cues may have had less impact on the paper cases than in actual practice. Fourth, the treatment choices and diagnostic judgments were made on separate occasions; this is unlike usual clinical practice. This was done purposely so that the physician would be forced to reconsider the set of cues when answering each question, but may thereby have caused more differences than occur in practice. Finally, the study was correlational and descriptive in nature. We attempted to infer process from the results, but, because we did not ask the physicians to vocalize their thoughts, we cannot be sure what the participants were thinking as they made their judgments. We pitted 2 processing models against each other and found that the sequential model prevailed for most participants but that the independent processing model prevailed for a significant minority. There may be other models that provide even better descriptions.

In spite of its limitations, our study suggests, in line with our own clinical experience, that in some circumstances a substantial number of clinicians make treatment decisions according to an independent processing model. We propose that, from the very beginning of and throughout their examination of a sick child, for example, busy clinicians ask themselves whether this child needs treatment and process the available information to answer this key question more or less inde- pendently of making a diagnosis. We suspect that in other circumstances-when teaching students and residents, when discussing the findings and plans with parents, and when describing their reasoning in the child's chart (and possibly to researchers) - these same clinicians are likely to insist on the importance of making the diagnosis before deciding about management.

This issue has practical as well as theoretical implications. Just as people's preferences or choices may reverse when they evaluate the same options comparatively or sequentially, ${ }^{10-12}$ incompatibilities between clinicians' diagnoses and treatment choices may, in theory, arise when they process independently the same diagnostic cues. Moreover, most of the educational and quality-improvement efforts aimed at students, residents, and practicing physicians are based on the classic model of decision making that may not always apply to day-to-day clinical medicine. As Kassirer and Kopelman point out, "For years, students in their first clinical rotations have been told to ignore therapeutic issues and concentrate on diagnosis." ${ }^{\text {(p220-1) }}$ Yet, if expert physicians do not make such a distinction, they ask, "Why continue to teach these practices as separate and distinct?" The educational focus may have to shift from diagnosis to treatment, ${ }^{7}$ that is, to focus less on leading clinicians to water than on teaching them better to choose whether or not to drink. ${ }^{44}$

\section{REFERENCES}

1. Barrows HS, Pickell GC. Developing Clinical Problem-Solving Skills: A Guide to More Effective Diagnosis and Treatment. New York, NY: WW Norton \& Company; 1991.

2. Pauker SG, Kassirer JP. The threshold approach to clinical decision making. N Engl J Med. 1980;302:1109-17.

3. Sox HC, Blatt MA, Higgins MC, Marton KI. Medical Decision Making. Boston, MA: Butterworth-Heinemann; 1988.

4. Gross R. Making Medical Decisions: An Approach to Clinical Decision Making for Practicing Physicians. Philadelphia, PA: American College of Physicians; 1999.

5. Kassirer JP, Kopelman RI. Learning Clinical Reasoning. Baltimore, MD: Williams \& Wilkins; 1991.

6. Shorter E. Doctors and Their Patients: A Social History. New Brunswick, NJ: Transaction; 1991.

7. Grenier B. Au nom de quoi décider? Rev Méd Intern. 1997;18: $250-4$.

8. Mullet E, Chartier D, Demerval R, Hermand D, Léoni V, Sastre MTM, Rulence-Pâques P, Siméone A. Jugement et éducation. L'orientation scolaire et professionnelle. 1996;25:531-55.

9. Slovic P. Preference reversals: a broader perspective. Am Econ Rev. 1983;73:596-605.

10. Mellers BA, Chang S, Birnbaum MH, Ordóñez LD. Preferences, prices, and ratings in risky decision-making. J Exp Psychol: Hum Percept Perform. 1992;18:347-61.

11. Hsee CK, Loewenstein GF, Blount S, Bazerman MH. Preference reversals between joint and separate evaluations of options: a review and theoretical analysis. Psychol Bull. 1999;125:576-90. 
12. González-Vallejo C, Moran E. The evaluability hypothesis revisited: joint and separate evaluation preference reversal as a function of attribute importance. Organ Behav Hum Decis Proc. 2001;86:216-33.

13. Vinson DC, Lutz LJ. The effect of parental expectations on treatment of children with a cough: a report from ASPN. J Fam Pract. 1993;37:23-7.

14. Cars H, Hakansson A. To prescribe-or not to prescribe-antibiotics: district physicians' habits vary greatly and are difficult to change. Scand J Prim Health Care. 1995;13:3-7.

15. Mangione-Smith R, McGlynn EA, Elliott MN, Krogstad P, Brook RH. The relationship between perceived parental expectations and pediatrician antimicrobial prescribing behavior. Pediatrics. 1999;103:711-8.

16. Shafir EB, Simonson I, Tversky A. Reason-based choice. In: Goldstein WM, Hogarth RM, editors. Research on Judgment and Decision-Making: Current, Connections, and Controversies. Cambridge, UK: Cambridge University Press; 1997, p. 69-94.

17. Kassirer JP, Gorry GA. Clinical problem solving: a behavioral analysis. Ann Intern Med. 1978;89:245-55.

18. González-Vallejo C, Sorum PC, Stewart TR, Chessare JB, Mumpower JL. Physicians' diagnostic judgments and treatment decisions about acute otitis media in children. Med Decis Making. 1998;18:149-62.

19. Cooksey RW. Judgment Analysis. New York, NY: Academic Press; 1996.

20. Wigton RS. Social judgement theory and medical judgement. Think Reason. 1996;2:175-90.

21. de Gramont S. The French: Portrait of a People. New York, NY: GP Putnam's Sons; 1969.

22. Payer L. Medicine and Culture: Varieties of Treatment in the United States, England, West Germany, and France. New York, NY: Penguin Books; 1988.

23. Sorum PC. Striking against managed care: the last gasp of la médecine libérale? JAMA. 1998;280:659-64.

24. Sorum PC. Two tiers of physicians in France: general pediatrics declines, general practice rises. JAMA. 1998;280:1099-101.

25. Hayden GF. Acute suppurative otitis media in children: diversity of clinical diagnostic criteria. Clin Pediatr. 1981;20:99-104.

26. Paradise JL. On classifying otitis media as suppurative or nonsuppurative, with a suggested clinical schema. J Pediatr. 1987;111:948-51.

27. Bluestone CD, Klein JO. Otitis media in infants and children. 2nd ed. Philadelphia, PA: WB Saunders; 1995.

28. Soussi T. Otite moyenne aiguë. In: Bourrillon A, editor. Pédiatrie pour le Practicien. 2nd ed. Paris: Masson; 1996. p. 456-8.

29. Mondain M. Symptomatologie clinique et diagnostic des otites et de leurs complications. Rev Prat 1998;48:843-7.
30. Froom J, Culpepper L, Grob P, et al. Diagnosis and antibiotic treatment of acute otitis media: report from International Primary Care Network. Br Med J. 1990;300:582-6.

31. Heikkinen T, Ruuskanen O. Signs and symptoms predicting acute otitis media. Arch Pediatr Adolesc Med. 1995;149:26-9.

32. Bauchner H, Adams W, Barnett E, Klein J. Therapy for acute otitis media: preference of parents for oral or parenteral antibiotic. Arch Pediatr Adolesc Med. 1996;150:396-9.

33. Alsarraf R, Jung CJ, Perkins J, Crowley C, Alsarraf NW, Gates GA. Measuring the indirect and direct costs of acute otitis media. Arch Otolaryngol Head Neck Surg. 1999;125:12-8.

34. Sorum PC. Measuring patient preferences by willingness to pay to avoid: the case of acute otitis media. Med Decis Making. 1999;19:27-37.

35. Heymann SJ, Toomey S, Furstenberg F. Working parents: what factors are involved in their ability to take time off from work when their children are sick? Arch Pediatr Adolesc Med. 1999;153:870-4.

36. Gorman CD, Clover WH, Doherty ME. Can we learn anything about interviewing real people form "interview" of paper people? Two studies of the external validity of a paradigm. Organ Behav Hum Perform. 1978;22:165-92.

37. Jones TV, Gerrity MS, Earp J. Written case simulations: do they predict physicians' behavior? J Clin Epidemiol. 1990;43:805-15.

38. Chaput de Saintonge DM, Hathaway NR. Antibiotic use in otitis media: patient simulations as an aid to audit. Br Med J. 1981;283:883-4.

39. Kirwan JP, Chaput de Saintogne DM, Joyce CRB, Currey HLF. Clinical judgment in rheumatoid arthritis: I: rheumatologists' opinions and the development of "paper patients." Ann Rheum Dis. 1983;42:648-51.

40. Chaput de Saintonge DM, Hattersley LA. Antibiotics for otitis media: can we help doctors agree? Fam Pract. 1985;2:205-12.

41. Brehmer A, Brehmer B. What have we learned about human judgment from thirty years of policy capturing? In: Brehmer B, Joyce CRB, editors. Human Judgment: The SJT View: Advances in Psychology. Amsterdam: North-Holland; 1988, p. 75-114.

42. Kirwan JR, Chaput de Saintogne DM, Joyce CRB. Clinical judgment analysis. Q J Med. 1990;76:935-49.

43. Peabody JW, Luck J, Glassman P, Dresselhaus TR, Lee M. Comparison of vignettes, standardized patients, and chart abstraction: a prospective validation study of 3 methods for measuring quality. JAMA. 2000;283:1715-22.

44. Poses RM, Cebul RD, Wigton RS. You can lead a horse to waterimproving physicians' knowledge of probabilities may not affect their decisions. Med Decis Making. 1995;15:65-75. 